\title{
PELATIHAN INSTALASI LISTRIK RUMAH TINGGAL DESA BINAAN BARU KEC. BELAWANG KAB. BARITO KUALA
}

\author{
Nurmahaludin ${ }^{1}$, Sarifudin ${ }^{2}$, Gunawan Rudi Cahyono ${ }^{3}$, Khairunnisa ${ }^{4}$ \\ Politeknik Negeri Banjarmasin ${ }^{1,2,3,4}$ \\ mahaludin@poliban.ac.id ${ }^{1}$ \\ sarif@poliban.ac.id ${ }^{2}$ \\ khairunnisa@poliban.ac.id ${ }^{3}$ \\ m4sgunnana@gmail.com ${ }^{4}$
}

\begin{abstract}
Most of community in Desa Binaan Baru village has jobs as farmers. Whereas in the dry season, many local youths migrated to the city to work. The purpose of this activity is to provide training for residential electrical installations so that the community has knowledge and skills in addition to farming so that it can be an alternative to get income. The method of carrying out activities is the provision of material in theory including the introduction of installation equipment and knowledge of installation drawings. Then proceed with the practice of simple electrical installations. Participants were divided into three groups with each accompanied by students who helped participants if they experienced difficulties during the training process. From the results of testing the installation circuit that has been done, it is obtained that each group can complete the practice material well.
\end{abstract}

Keywords: installation training, residential electricity installation, Binaan Baru village

\begin{abstract}
ABSTRAK
Sebagai besar masyarakat desa Desa Binaan Baru memiliki pekerjaan sebagai petani. Sedangkan pada musim kering, banyak pemuda setempat yang merantau ke kota untuk bekerja. Tujuan dari kegiatan pengabdian ini adalah memberikan pelatihan instalasi listrik rumah tinggal agar masyarakat memiliki pengetahuan dan bekal keterampilan selain bertani sehingga bisa menjadi alternatif penghasilan tambahan. Metode pelaksanaan kegiatan adalah pemberian materi secara teori meliputi pengenalan peralatan instalasi dan pengetahuan mengenai gambar instalasi. Kemudian dilanjutkan dengan praktek instalasi listrik sederhana. Peserta dibagi menjadi tiga kelompok dengan masing-masing didampingi oleh mahasiswa yang membantu peserta jika mengalami kesulitan selama proses pelatihan. Dari hasil pengujian rangkaian instalasi yang telah dikerjakan, diperoleh masing-masing kelompok dapat menyelesaikan materi praktek dengan baik.
\end{abstract}

Kata Kunci: pelatihan instalasi, instalasi listrik rumah tinggal, desa Binaan Baru

\section{PENDAHULUAN}

Kecamatan Belawang merupakan salah satu dari 17 kecamatan yang ada di Kabupaten Barito Kuala, Kalimantan Selatan. Kondisi geografis sebagian besar terdiri dari lahan rawa gambut, sehingga mata pencaharian didominasi oleh sektor pertanian (93.4\%). Kecamatan Belawang mempunyai luas $80.25 \mathrm{~km}^{2}$ dan terdiri dari 13 desa yaitu [1] :

1. Desa Binaan Baru

2. Desa Rangga Surya 
3. Desa Karang Buah

4. Desa Karang Dukuh

5. Desa Samuda

6. Desa Murung Keramat

7. Desa Sungai Seluang Pasar

8. Desa Sungai Seluang

9. Desa Belawang

10.Desa Parimata

11.Desa Patih Selera

12.Desa Bambangin

13.Desa Sukaramai

Mata pencaharian sebagian besar penduduk di Desa Binaan Baru adalah bertani. Sedangkan pada musim kering, banyak pemuda setempat merantau ke kota untuk bekerja. Di sisi lain, pertumbuhan perumahan yang meningkat di desa Binaan Baru membuka peluang usaha baru berupa instalatir listrik. Penguasaan pengetahuan dan keterampilan instalasi listrik selain dapat menjadi usaha tambahan, setidaknya dapat menjadi solusi bagi kurang tertatanya instalasi di rumah tinggal penduduk. Sehingga dapat menekan bahaya yang mungkin ditimbulkan seperti hubungan pendek dan kebakaran.

Tujuan kegiatan ini adalah memberikan pelatihan instalasi listrik rumah tinggal bagi masyarakat desa khususnya pemuda. Manfaat kegiatan adalah pemuda memiliki pengetahuan dan keterampilan dasar (life skill) dalam bidang instalasi listrik rumah tinggal. Target dari kegiatan ini adalah peserta pelatihan akan mempunyai pengetahuan dan keterampilan dasar dalam bidang instalasi listrik rumah tinggal. Luaran kegiatan berupa modul kerja dan bantuan perangkat peralatan untuk instalasi.

\section{METODE KEGIATAN}

Metode pelaksanaan kegiatan pelatihan instalasi listrik di desa mitra ditunjukkan dalam Gambar 1. 


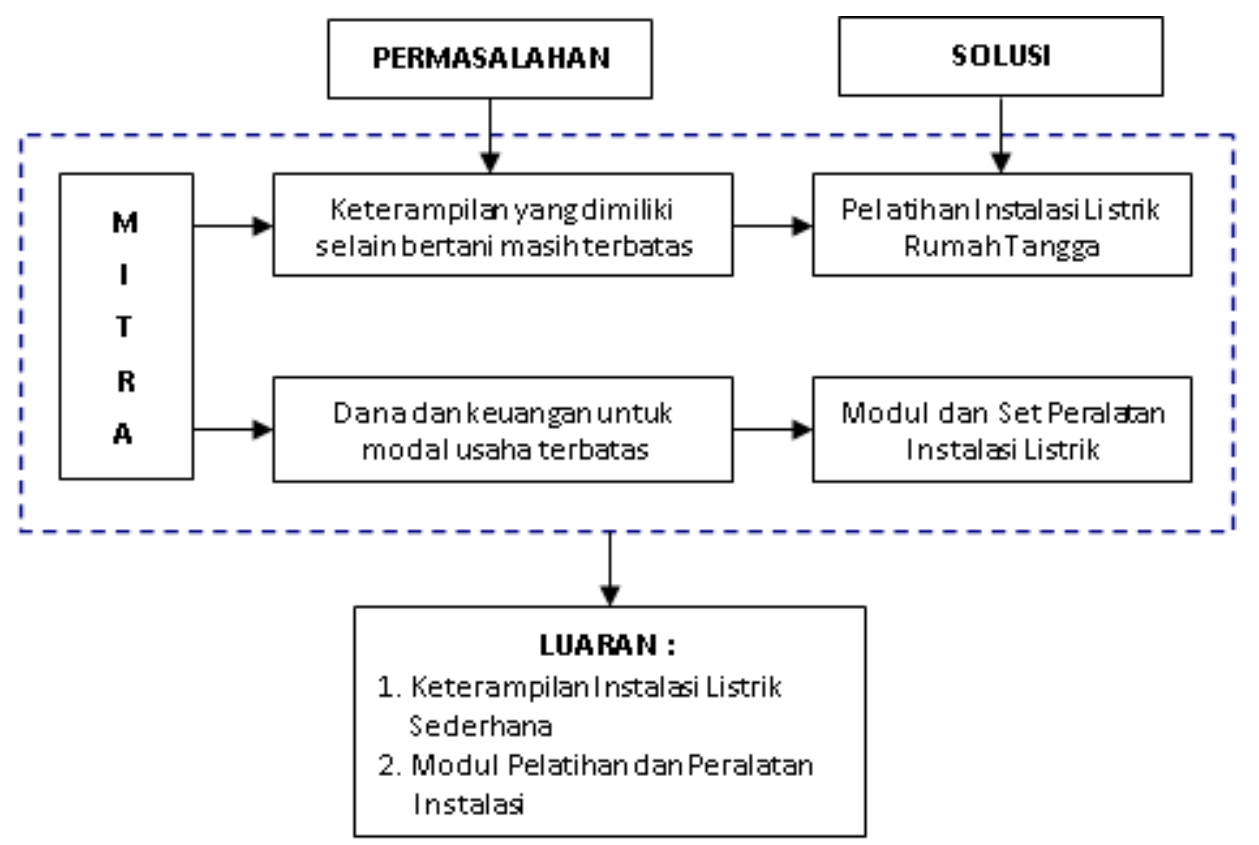

Gambar 1. Metode Pelaksanaan Kegiatan Pengabdian

Tahapan yang dilakukan dalam pelaksanaan pengabdian adalah sebagai berikut.

1. Menyusun materi yang akan digunakan untuk pelatihan, meliputi:

a. Pengenalan peralatan instalasi listrik

Peralatan dan bahan instalasi listrik yang digunakan dalam pelatihan ditunjukkan dalam Tabel 1.

Tabel 1. Alat dan Bahan Pelatihan

\begin{tabular}{|l|l|l|}
\hline No. & Alat & Bahan \\
\hline 1 & Tang kombinasi & Kabel NYA \\
2 & Tang lancip & Pipa \\
3 & Cutter & T doos \\
4 & Test pen & Saklar tunggal \\
5 & Obeng plus (+) & Stop kontak \\
6 & Obeng minus (-) & Klem pipa \\
7 & Palu & L bow \\
8 & Papan kerja & Lampu \\
9 & AVO meter & Fitting \\
10 & Penggaris besi & Isolasi \\
11 & Gergaji triplek & MCB \\
\hline
\end{tabular}

b. Pengenalan gambar dasar instalasi listrik

Diagram pengawatan (wiring diagram) dan gambar kerja instalasi listrik untuk kegiatan pelatihan ditunjukkan dalam Gambar 2. 


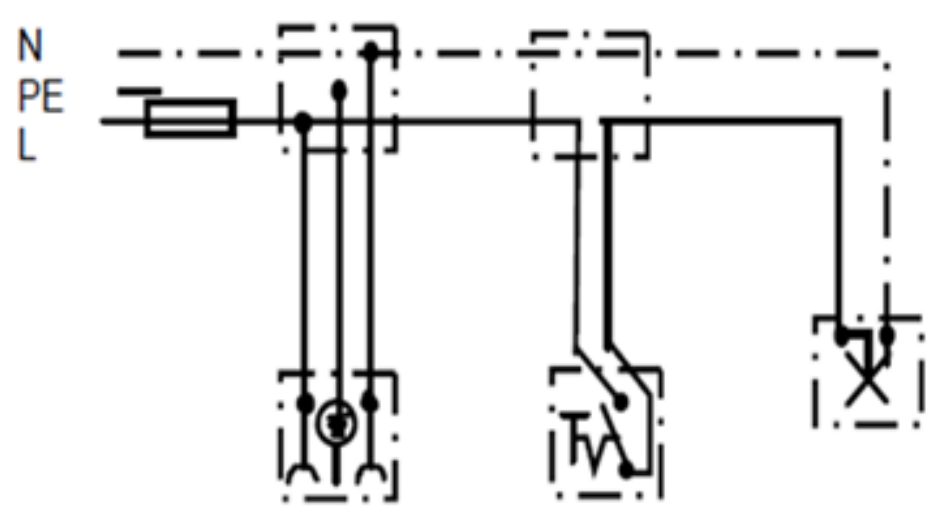

Gambar 2. Diagram Pengawatan Instalasi Listrik http://www.academia.edu

2. Pelaksanaan pelatihan bagi peserta

3. Pemberian bantuan berupa set peralatan instalasi

\section{HASIL DAN PEMBAHASAN}

Pelaksanaan pelatihan dibagi menjadi dua sesi yaitu secara teori memberikan materi dan dilanjutkan dengan praktek pemasangan instalasi. Tahap pertama memberikan materi mengenai bahan dan peralatan yang digunakan serta beberapa permasalahan yang ditemui dalam instalasi listrik (Gambar 3).

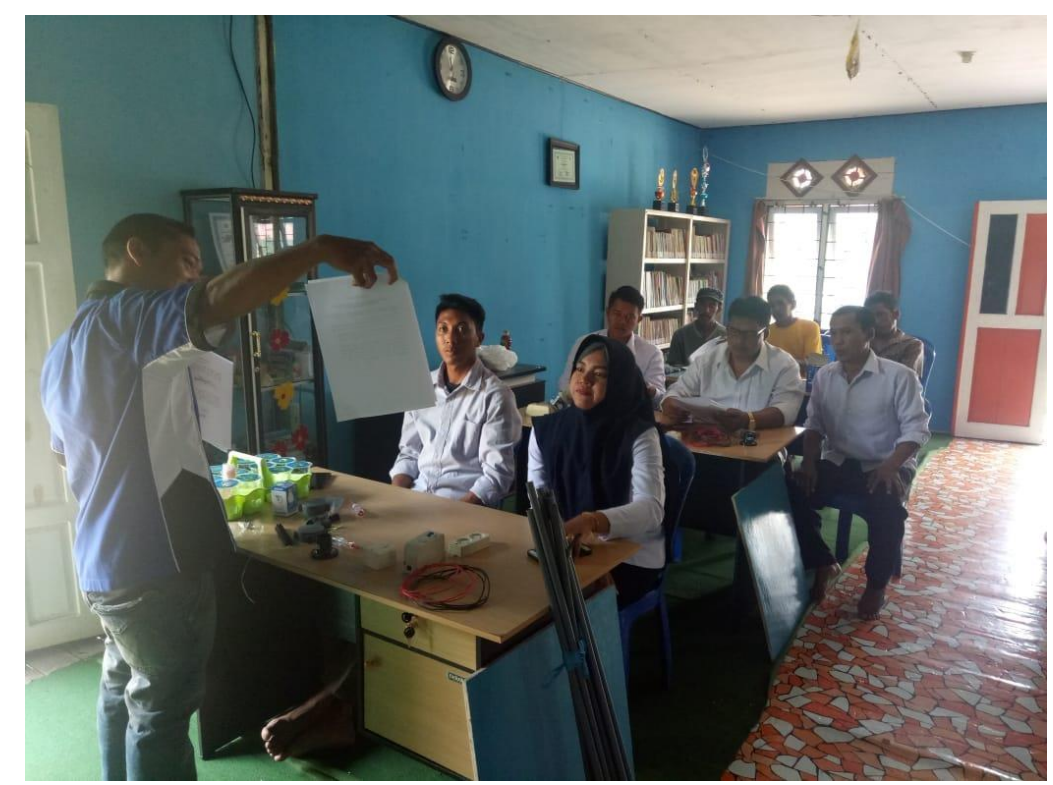

Gambar 3. Pemberian Materi Pelatihan

Tahap berikutnya adalah memberikan pelatihan teknik dasar instalasi listrik rumah tinggal. Peserta diminta untuk memasang instalasi listrik dengan sebuah stok kontak, sebuah saklar tunggal, dan sebuah MCB untuk menyalakan lampu seperti ditunjukkan dalam Gambar 4. 


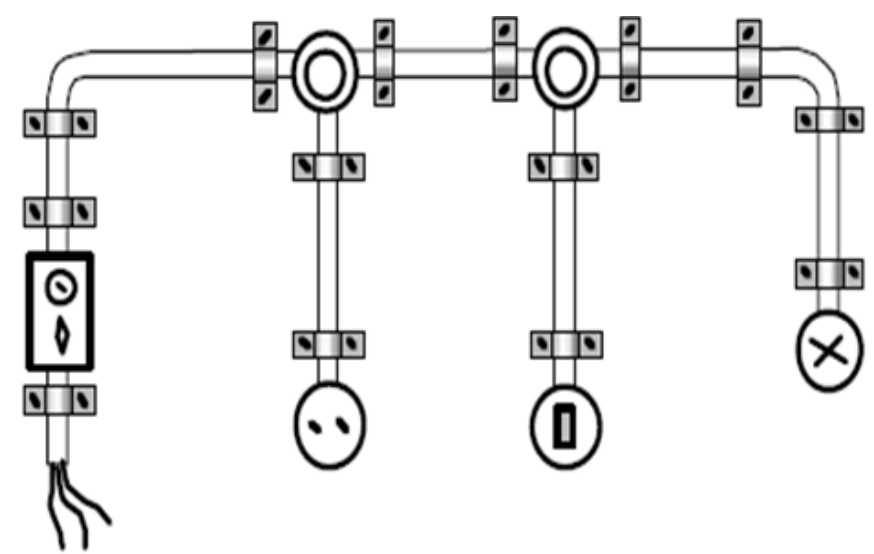

Gambar 4. Gambar Kerja Instalasi Listrik http://www.academia.edu

Kegiatan diikuti oleh 9 peserta yang dibagi menjadi 3 kelompok kerja (Gambar 5). Tiap kelompok didampingi oleh 2 orang mahasiswa untuk membantu peserta yang mengalami kesulitan dalam pelatihan instalasi.

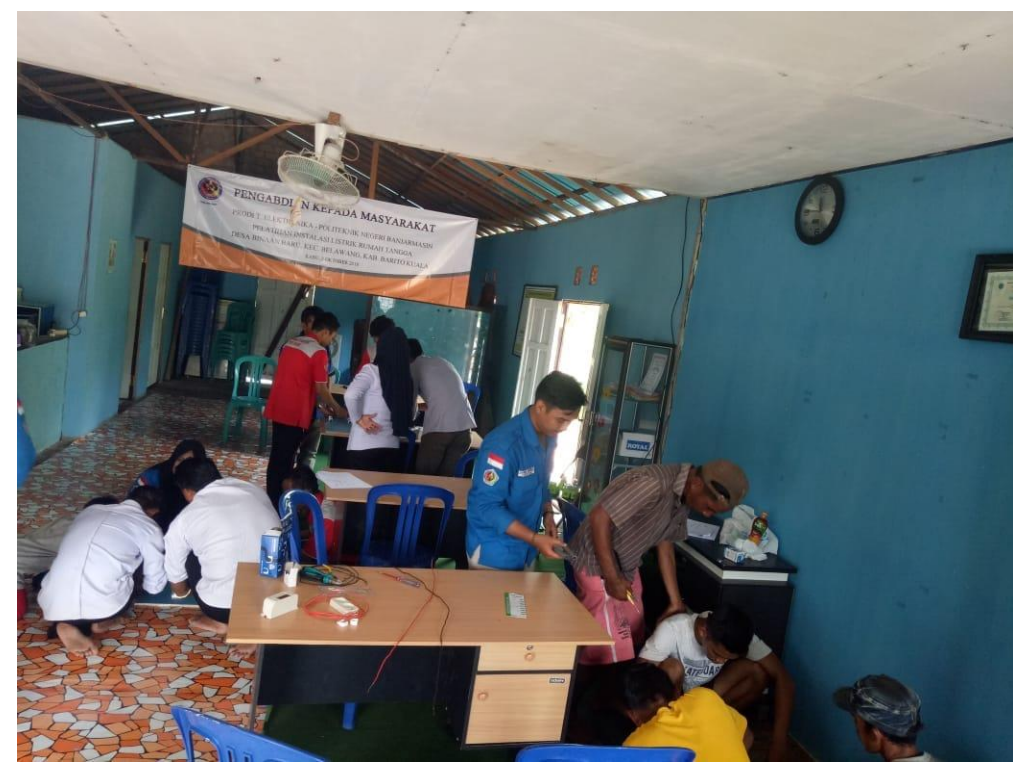

Gambar 5. Peserta Pelatihan Dibagi Menjadi 3 Kelompok

Proses kegiatan selama pelatihan ditunjukkan dalam Gambar 6 dan Gambar 7. Sedangkan Gambar 8 menunjukkan proses pengujian rangkaian untuk menyalakan sebuah lampu. 


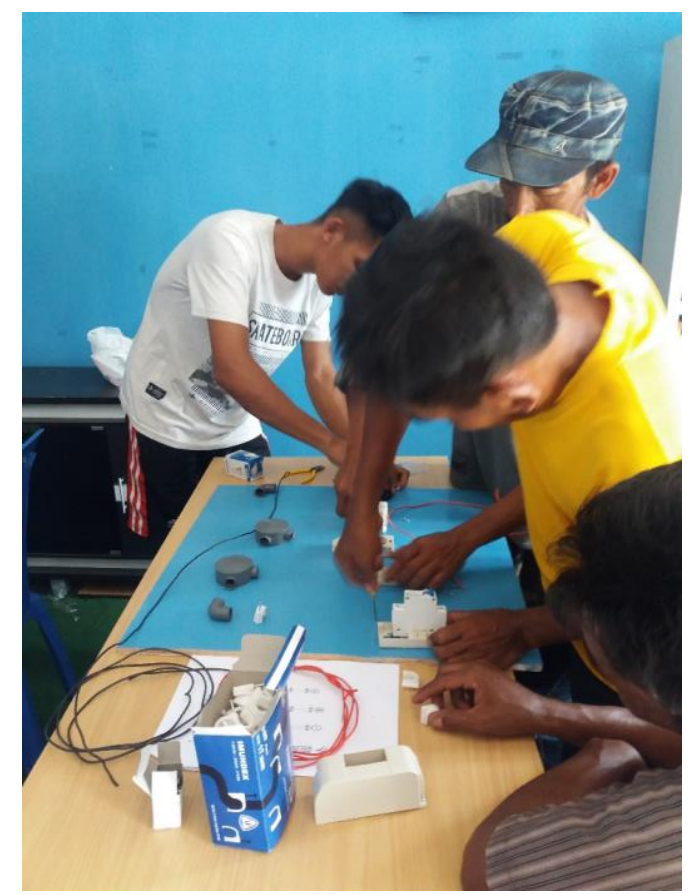

Gambar 6. Proses Pemasangan Instalasi

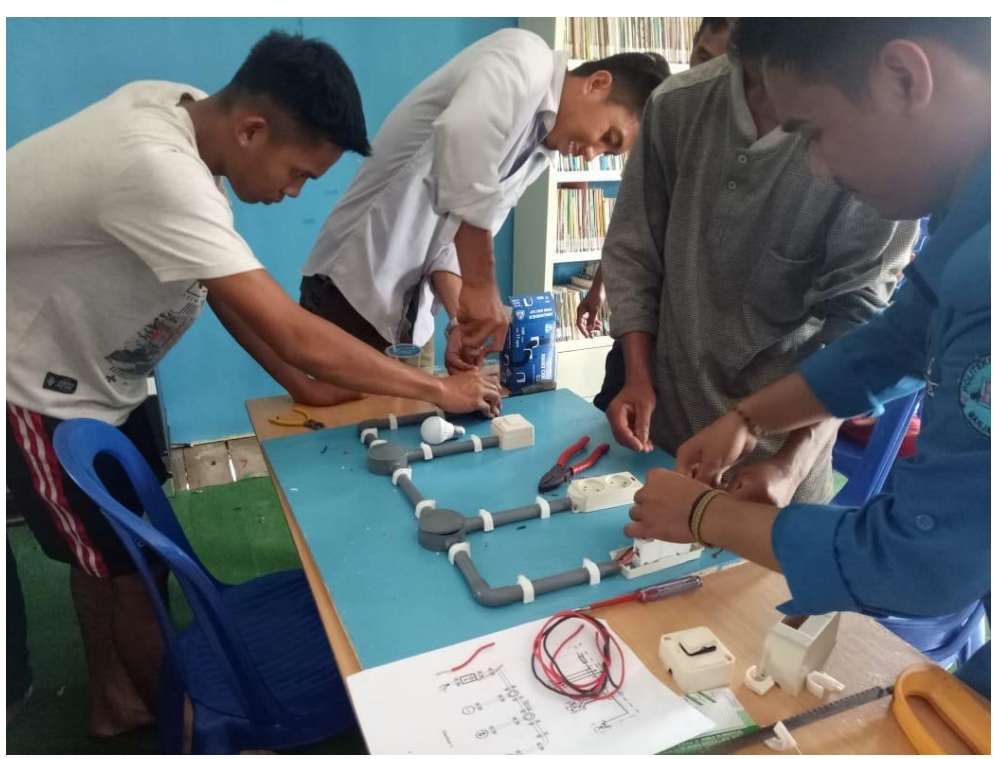

Gambar 7. Pemasangan Pipa Instalasi 


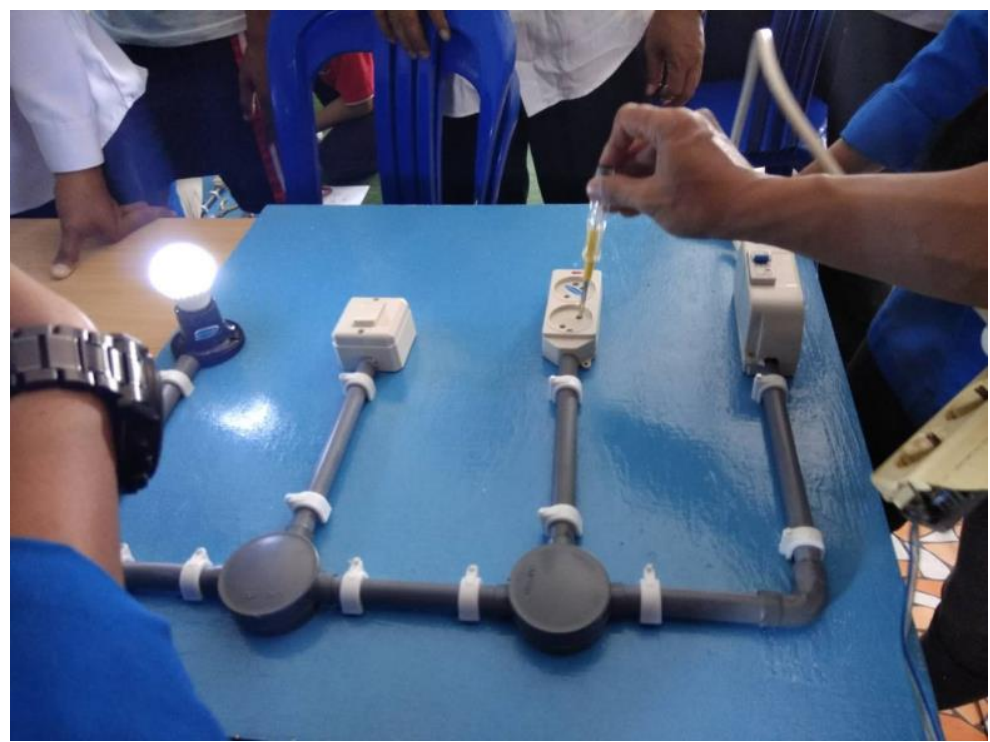

Gambar 8. Proses Pengujian Instalasi

\section{KESIMPULAN}

Materi yang diberikan adalah dasar-dasar instalasi listrik rumah tinggal berupa rangkaian instalasi sederhana dengan skalar tunggal. Secara umum, peserta pelatihan dapat memahami materi yang diberikan serta antusias melaksanakan praktek pelatihan. Peserta dibagi dalam 3 kelompok dimana tiap kelompok terdiri dari 3 orang. Masing-masing kelompok dapat menyelesaikan tugas praktek yang diberikan.

\section{UCAPAN TERIMA KASIH}

Kami ucapkan terimakasih banyak kepada Poliban melalui unit P3M yang telah membantu dalam pemberian dana hibah kegiatan pengabdian masyarakat.

\section{DAFTAR PUSTAKA}

http://kecamatanbelawang.blogspot.co.id/2014/05/gambaran-umum-kecamatanbelawang.html

http://www.academia.edu 